\title{
Virtual Power Electronics Labs for Online Teaching
}

\author{
Mohamed Darwish \\ Department of Electronic and \\ Computer Engineering, \\ Brunel University \\ London, UK \\ mohamed.darwish@Brunel.ac.uk
}

\author{
Hassan Amreiz \\ London College UCK, \\ London, U.K. \\ h.amreiz@lcuck.ac.uk
}

\author{
Alan Janbey \\ London College UCK, \\ London, U.K. \\ a.janbey@lcuck.ac.uk
}

\author{
Christos Marouchos \\ Department of Electrical \\ Engineering, \\ Cyprus University of \\ Technology \\ Limassol, Cyprus \\ christos.marouchos@cut.ac.cy
}

\begin{abstract}
A textbook and traditional classroom only approach in teaching power electronics can mean that design of power electronic circuits could be isolated and will be difficult to absorb by students. If we add to this, the sudden switch to virtual delivery of lectures then the challenge to engage the students in the learning process of power electronics could be even more complicated. In this paper, a virtual way of teaching power electronic circuits without much compromise with real practical environment is presented. A boost and flyback converter circuits are presented as a case study where all practical parameters are considered in the 'virtual' practical circuit.
\end{abstract}

Keywords - Virtual Labs, Online electric labs, Online teaching.

\section{INTRODUCTION}

Online courses became very popular within the last few years even before the global spread of COVID-19 [1-4]. They provide several advantages like flexibility, comfort, self-paced learning, lower total cost and career development. For many years, most of the online courses were considered for courses like business, management, social sciences, etc. However, the growth of online courses has not been without challenges. There was (and still is) constant criticism and some question marks about the quality control particularly when it comes to topics like power electronics where it is considered as unsuitable for online delivery due to the lack of hands on experience which is required for engineering subjects in general.

Simulation packages are considered as a supplement to practical work and not as a replacement. With the unfortunate spread of COVID-19 and with the desperate attempt to go for online education delivery in many countries, perhaps it is a good time to revisit the suitability of online teaching for power electronic courses. In this paper, the authors present examples of carrying out 'virtual' practical design of a power electronic circuit where detailed parameters like losses and real characteristics of the semiconductor switch are considered. Although the OrCAD (PSPICE) is used in this paper but there are other packages where real devices available in the software library can be used. Some of these software packages include LTspice, Multisim, PSIM, Saber, SIMetrix/SIMPLIS, etc. Most of educational use of these packages focus on the ideal devices while the industry focus of the real devices. The issue of using the real devices (semiconductor switches, etc.) in these packages is the long simulation time and the problem of the simulation not converging. For these reasons, lecturers and students go for easy solution by selecting ideal components. Perhaps there is a need for these packages to be developed further in order to allow for virtual experiments without the complexity of long simulation time and convergence problems. One way of overcoming this problem is to divide large power electronic circuit into sub-circuits [5].

The case study presented in this paper are popular boost and flyback converter circuits where two modes of simulations are carried out, one with the ideal component (for boost converter) and the other with 'virtual' real components (for both boost and flyback converters). However, before going to the simulation phase, a brief design is introduced first.

\section{DESIGN AND SimUlATION OF IDEAL BoOST CONVERTER}

Fig. 1 shows a typical boost converter where the input voltage can be stepped up through the control of the switch duty cycle $(D)$ while the power 'theoretically' will remain the same.

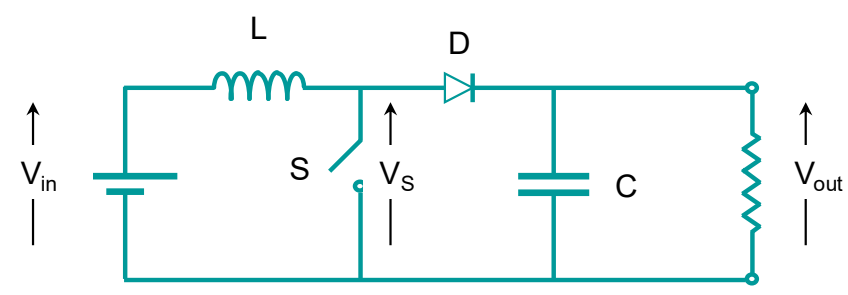

Fig. 1: An ideal boost converter circuit 
This article has been accepted for publication in a future issue of this journal, but has not been fully edited. Content may change prior to final publication. Citation information: DOI10.1109/UPEC49904.2020.9209772, 2020 55th International Universities Power Engineering

The switch duty cycle, $\mathrm{t}_{\mathrm{on}}$ and $\mathrm{t}_{\mathrm{off}}$ can be expressed as:

$$
\begin{aligned}
& D=t_{\text {on }} /\left(t_{\text {on }}+t\right) \\
& T=t_{\text {off }}+t_{\text {off }} \\
& t_{\text {on }}=D T \\
& t_{\text {off }}=(1-D) T
\end{aligned}
$$

The inductor current will rise and fall during the turn-on and turn-off times. Assuming that the inductor current remains continuous, (i.e. the energy stored in the inductor does not drop to zero) then the 'turn-on' and the 'turn-off' of the switch can be analyzed separately with respect to Fig. 2 . It has to be noticed that this only covers the steady state analysis of the circuit and assuming ideal inductor with zero internal resistance and lossless switch.

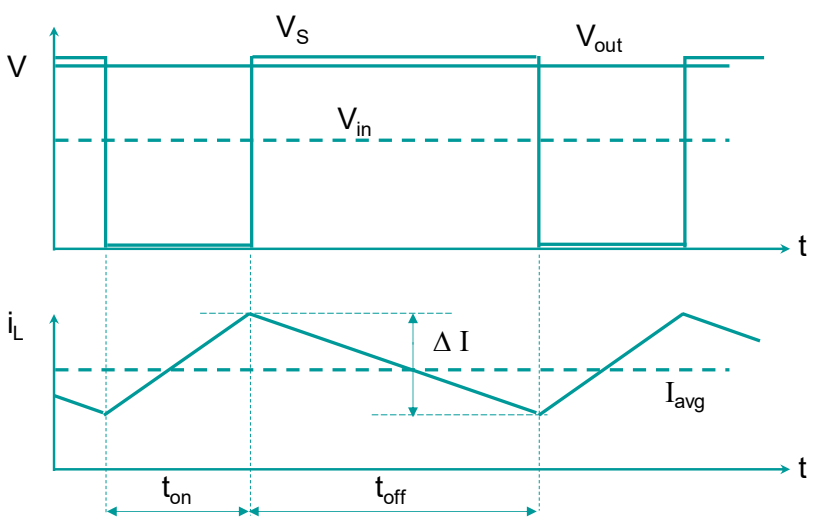

Fig. 2: Voltage and current waveforms in ideal boost converter

\section{A. S is closed}

When the switch ' $S$ ' is closed a voltage, $v$ appears across the inductor ' $L$ ' during the time $t_{o n}$. If $L$ is finite, then there will be a small increase in the current through it, $\Delta I$ (on).

$\Delta I_{(o n)}=V_{\text {in }} D T / L$

\section{B. Sis open}

When the switch ' $S$ ' is open A voltage, $v_{\text {in }}-v_{\text {out }}$ (negative voltage) appears across ' $L$ ' during $t_{\text {off }}$. The result is a small decrease in the current:

$\Delta I_{\text {off }}=\left(V_{\text {in }}-V_{\text {out }}\right)(1-D) T / L$

In the steady state equation (5) equals equation (6): $\Delta I_{\text {on }}+\Delta I_{\text {off }}=0$

$V_{\text {in }} D T / L+\left(V_{\text {in }}-V_{\text {out }}\right)(1-D) T / L=0$

Solve for $V_{\text {out }}$

$V_{\text {out }}=V_{\text {in }} /(1-D)$
Since ' $D$ ' lies between 0 and $1 V_{\text {out }}$ is greater than $V_{\text {in }}$ and of the same polarity.

$V_{\text {out }}$ can be varied by PWM (changing ' $D$ ').

The inductance value is not critical, but there are several factors that influence its choice:

- $\mathrm{I}_{\max }$ depends on $\Delta I$, so to minimise the switch and diode current ratings $\mathrm{L}$ should be large.

- The losses in the practical switch and diode increase somewhat as $I_{\max }$ increases, so $L$ should be large.

- The cutoff frequency of the output ' $L C$ ' filter is $\omega=$ $1 / \sqrt{ }(L C)$. For a given filtering effect, there is a trade-off between $L$ and $C$.

- To minimise the ripple current rating of $C, L$ should be large.

- To ensure continuous mode of operation, $L$ should be large.

- However, from size, weight and cost considerations we would like $L$ to be as small as possible.

$$
\begin{aligned}
& V_{\text {out }}=\frac{V_{\text {in }}}{1-D} \\
& L=\frac{V_{\text {in }} D}{\Delta i_{L} f}
\end{aligned}
$$

The minimum inductor value, assuming the inductor current is just continuous, can be expressed as:

$$
L_{\text {min }}=\frac{D(1-D)^{2} R}{2 f}
$$

It has to be noticed that any drop in the inductor value due to temperature change can cause the circuit to operate in the discontinuous mode of operation and equation (11) will not be valid any more.

The choice of the capacitor is theoretically determined by the amount of voltage ripple acceptable at the output.

$$
C=\frac{D}{R f\left(\frac{\Delta V_{\text {out }}}{V_{\text {out }}}\right)}
$$

\section{Numerical example}

Design a boost converter with the following specifications: $\mathrm{V}_{\text {in }}=12 \mathrm{~V}, \mathrm{~V}_{\text {out }}=24 \mathrm{~V}$, Power $=25 \mathrm{~W}$, Output ripple voltage $\leq 1 \%$, Switching frequency $=20 \mathrm{kHz}$.

The load ' $\mathrm{R}$ ' can be calculated from the load power $(25 \mathrm{~W})$ and $\mathrm{V}_{\text {out }}(24 \mathrm{~V})$ to be $23.04 \Omega$. The values of the duty cycle 'D', 'L', and 'C' can be calculated from equations (9), (11), and (12);

$D=0.5$

$L=72 \mu H$

$C=108.5 \mu F$ 

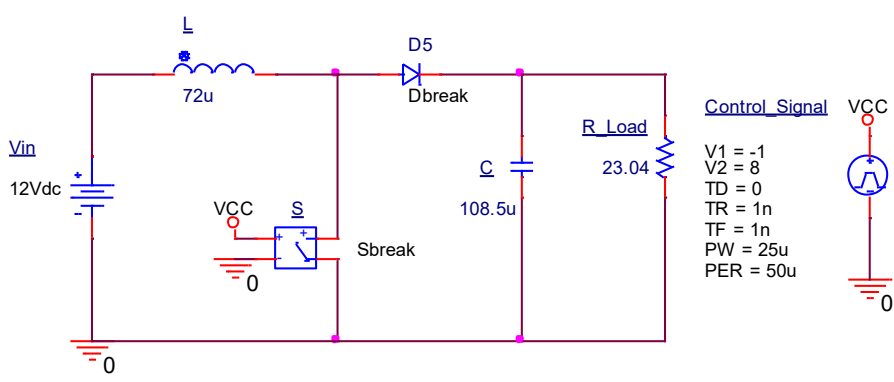

Fig. 3: PSPICE circuit for ideal boost converter

Putting these values in an ideal PSPICE circuit (ideal components shown in Fig. 3), gives the predicted voltage and current waveforms (Fig. 4).

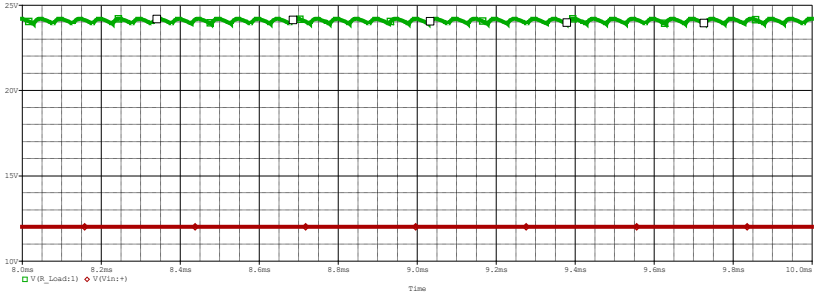

Fig. 4: Input (red) and output (green) in the ideal boost converter (y-axis range $10 \mathrm{v}-25 \mathrm{v}, \mathrm{x}$-axis range $8 \mathrm{~ms}-10 \mathrm{~ms})$

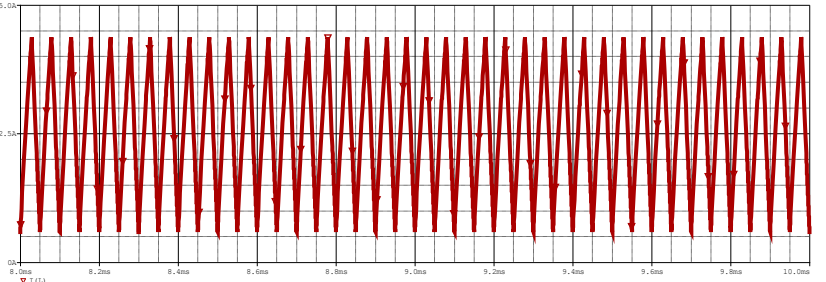

Fig. 5: Inductor current in the ideal boost converter (y-axis range $0-5 \mathrm{~A}$, $\mathrm{x}$-axis range $8 \mathrm{~ms}-10 \mathrm{~ms})$

The ideal circuit simulation is straightforward; however, it does not tell us the practicality of the circuit. The switch is ideal and the inductor, capacitor and diode have zero resistances. The efficiency of such circuit cannot be investigated due to the ideal components. It is good to give the student an overall view of how boost converter works but not more than that.

\section{DESIGN AND SiMULATION OF 'VIRTUAL' PRACTICAL BOOST CONVERTER}

Since the inductor in the practical boost converter circuit is not ideal and it has some internal resistance (r), the relationship between the input and output voltages in equation (9) is not valid anymore and can be replaced by equation (13):

$$
V_{\text {out }}=\left(\frac{V_{\text {in }}}{1-D}\right)+\left(\frac{1}{1+r_{L} /\left[R(1-D)^{2}\right]}\right)
$$

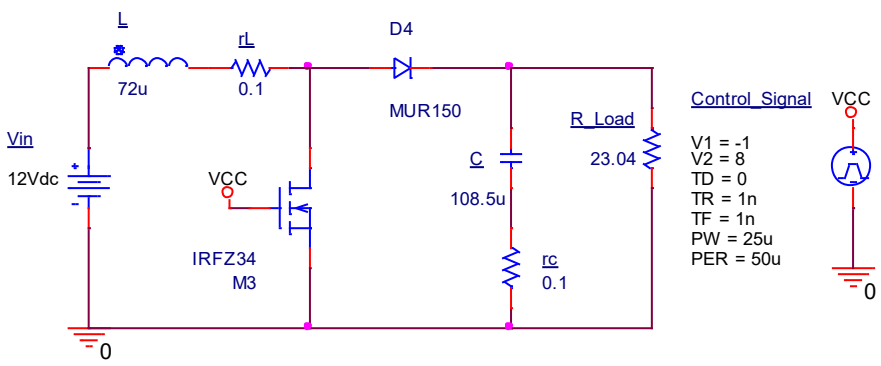

Fig. 6: PSPICE circuit for a 'virtual' practical boost converter

In Fig. 6 the ideal switch has been replaced with IRFZ34 MOSFET and the ideal diode has been replace with MUR150 diode. The inductor and capacitor both include internal resistance (chosen as $0.1 \Omega$ in this example). Fig. 7 shows the drop of the output voltage in comparison to Fig. 4. This is mainly due to the characteristics of the MOSFET and voltage drop across the inductor that was ignored in the ideal simulation. Students are expected to compensate that drop in the output voltage by increasing the MOSFET duty cycle.

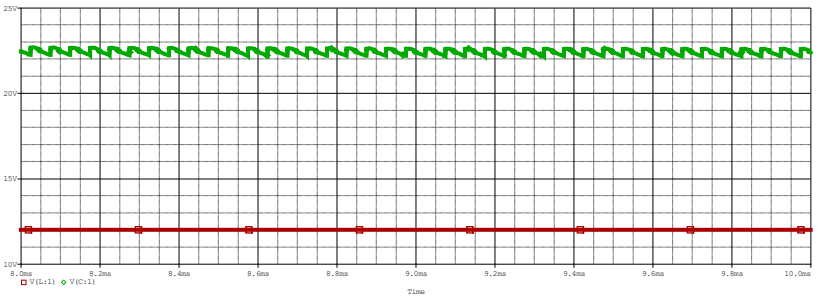

Fig. 7: Input (red) and output (green) in the 'virtual' practical boost converter (y-axis range $10 \mathrm{v}-25 \mathrm{v}, \mathrm{x}$-axis range $8 \mathrm{~ms}-10 \mathrm{~ms}$ )

Fig. 8 also illustrates that the inductor current becomes very close to the discontinuous mode of operation, which means that the calculated value should be multiplied by a factor of 1.2 or 1.25 to ensure continuous mode of operation.

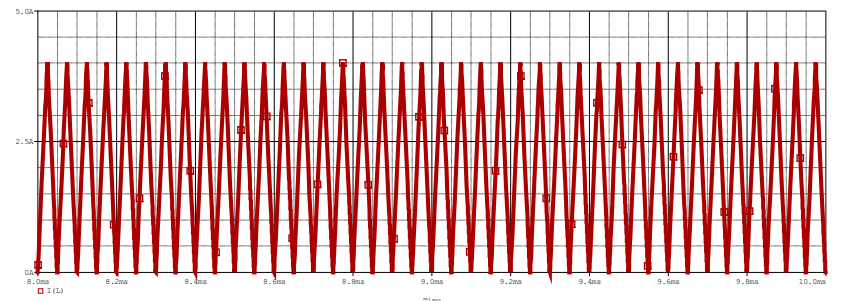

Fig. 8: Inductor current in the 'virtual' practical boost converter (y-axis range $0 \mathrm{~A}-5 \mathrm{~A}, \mathrm{x}$-axis range $8 \mathrm{~ms}-10 \mathrm{~ms}$ )

Ignoring the internal resistance of the boost inductor can have a major effect on the output voltage. In ideal boost converter, the gain of the boost converter can go to infinity at $\mathrm{D}=1$, however, as Fig. 9 illustrates the gain is restricted because of the internal resistance (r). 
This article has been accepted for publication in a future issue of this journal, but has not been fully edited. Content may change prior to final publication. Citation information: DOI10.1109/UPEC49904.2020.9209772, 2020 55th International Universities Power Engineering Conference (UPEC)

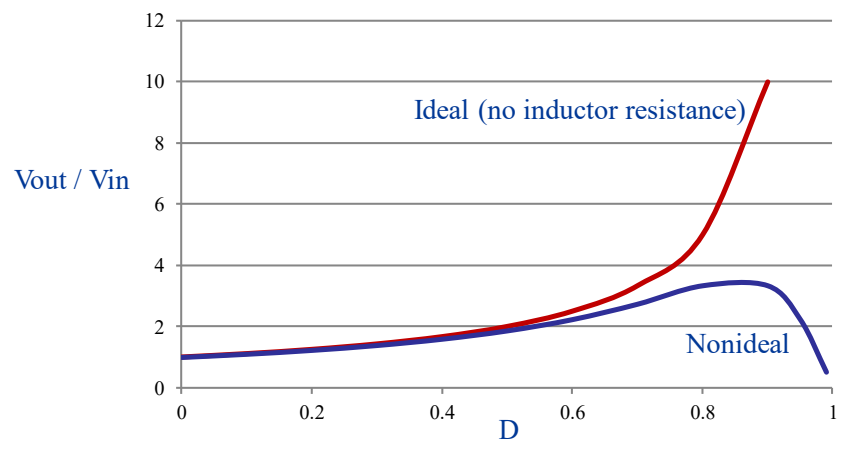

Fig. 9: Effect of inductor internal resistance on the gain

\section{StUdy OF LOSSES IN 'VIRTUAL’ Practical Boost CONVERTERS}

Since real devices (well, virtual real devices) are used in the simulation, then the losses can be studied in the boost converter circuit. The efficiency of the converter as well as the input and output powers are shown in Fig. 10.

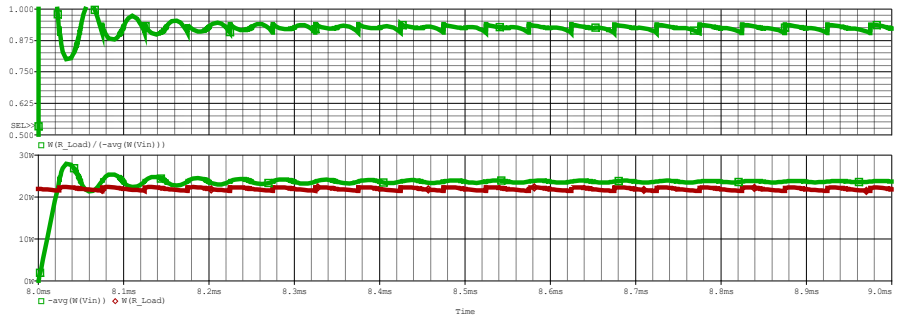

Fig. 10: Top graph: Efficiency of the converter (92\%). Bottom graph: Input and output powers (green $24 \mathrm{~W} \&$ red $22 \mathrm{~W}$ )

It is also important to study the losses in the 'virtual' practical MOSFET, hence students can decide on any cooling requirements or heatsink sizing. Fig. 11 shows the switching losses (red trace) together with the voltage across the switch (green trace). It can be seen that the turn-off losses is much higher than the turn-on losses. Such information is very important when it comes to the designing of snubber circuits.

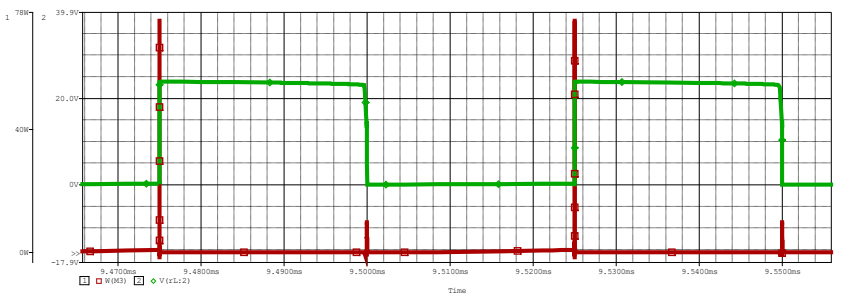

Fig. 11: Switching losses (red) and voltage across MOSFET (green) (y-axis range $-17.9 \mathrm{v}-39.9 \mathrm{v} \& 0 \mathrm{~W}-78 \mathrm{~W}$, $\mathrm{x}$-axis range $9.47 \mathrm{~ms}-9.55 \mathrm{~ms}$ )
Conduction losses in the MOSFET (Fig. 12) can also be observed. Such information is also very important when connecting MOSFETs in parallel for high current application circuits.

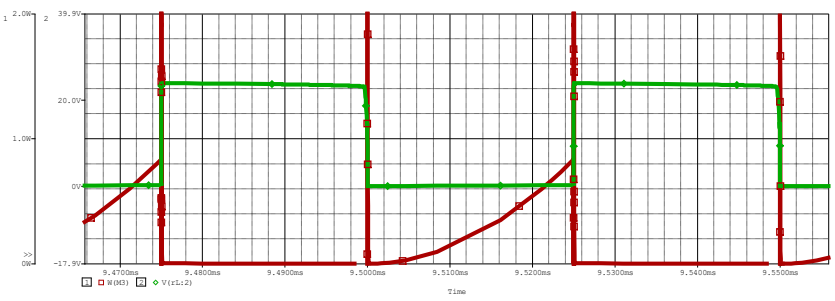

Fig. 12: Conduction losses (red) and voltage across MOSFET (green) (y-axis range $-17.9 \mathrm{v}-39.9 \mathrm{v} \& 0 \mathrm{~W}-78 \mathrm{~W}$, $\mathrm{x}$-axis range $9.47 \mathrm{~ms}-9.55 \mathrm{~ms}$ )

\section{StUdy OF 'ViRTUAL' PRACTICAL Flyback CONVERTER}

Another example to demonstrate the 'virtual' teaching of power electronic converters is the Flyback converter. The inductor in the well-known buck-boost converter is split to form a transformer, so that the voltage ratios are multiplied with an additional advantage of galvanic isolation between the input and output. The flyback converter in this example (shown in Fig. 13) operates in the 'buck' mode. A similar MOSFET switch, as the one used in the boost converter, is used in the virtual circuit (IRFZ34). $\mathrm{V}_{\text {in }}=100 \mathrm{~V}, \mathrm{~V}_{\text {out }} 31 \mathrm{~V}$ and the duty cycle ' $\mathrm{D}$ ' is calculated at 0.25 .

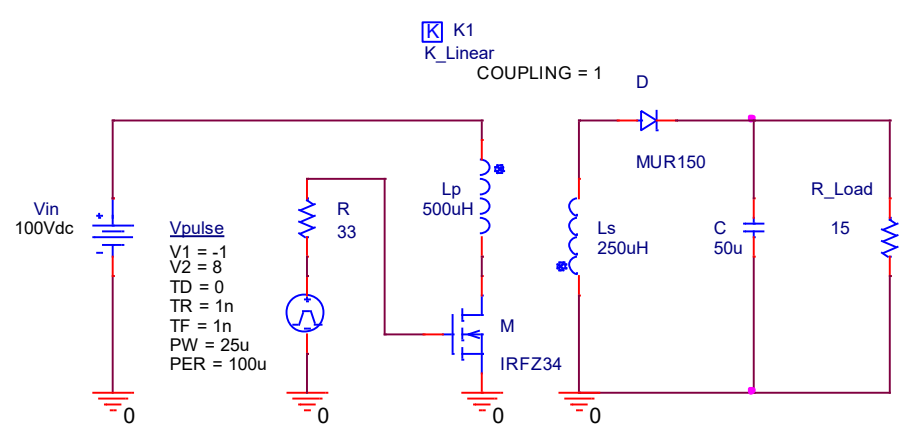

Fig. 13: PSPICE circuit for a 'virtual' practical Flyback Converter

The bottom trace in Fig. 14 shows the input voltage (100V) the output voltage (31V), and most importantly, it shows the voltage across the MOSFET in the top trace (in green). It displays the resonance, which the MOSFET switch is subjected to from the 'off' to the 'on' state. 


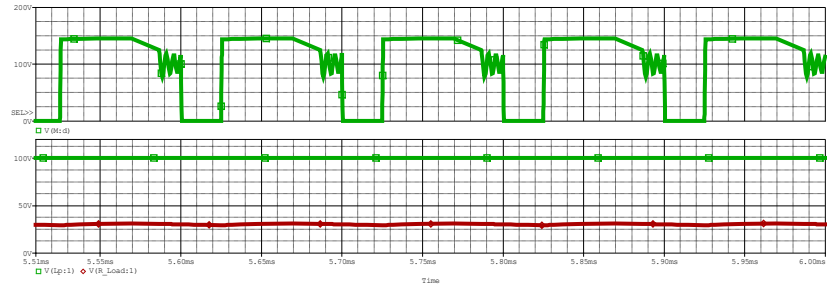

Fig. 14: Voltage across the MOSFET switch (top trace) and the input \& voltages of the flyback converter (y-axis range $0 \mathrm{v}-200 \mathrm{v} \& 0 \mathrm{v}-100 \mathrm{v}$, $\mathrm{x}$-axis range $5.51 \mathrm{~ms}-6 \mathrm{~ms})$

Although the coupling of the two inductors is set at ' 1 ' but students can see the effect of the circuit performance at different ' $k$ ' values. For example, the same waveforms in Fig. 14 is displayed at Fig. 15 after changing the coupling ' $k$ ' to 0.8 instead of 1 . It can be seen that the resonance effect during the 'switching off' is more significant than that of the 'switching on'.

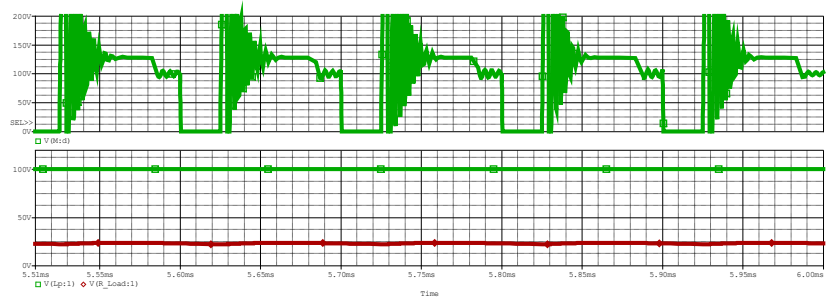

Fig. 15: Effect of varying the inductor coupling ' $k$ ' on voltage across the MOSFET (top trace) and the input \& output voltages (bottom trace) (yaxis range $0 \mathrm{v}-200 \mathrm{v} \& 0 \mathrm{v}-7100 \mathrm{v}$, $\mathrm{x}$-axis range $5.51 \mathrm{~ms}-6 \mathrm{~ms}$ )

\section{CONCLUSIONS}

Most of the power-electronics simulation teaching is carried out using ideal devices this is mainly because the focus is on the control and system operation. The practical work then complement the simulation study and provides values like efficiency and losses measurements. The authors in this paper are revisiting the power-electronics simulation technology where the simulation work can be carried out, not as a replacement to practical work, but to give a more accurate operation of power electronic circuits. In this virtual lab, actual devices are used from the software library in order to have more realistic study of power electronics devices. Also with the intention to move more and more towards online courses, ideal semiconductor switches and ideal components are better to be modeled with virtual component with real information that can be extracted from the relevant datasheets. Two power electronic converter topologies are presented in this paper. In both circuits, the simulation of real characteristics of the
MOSFET switches and also with the consideration of internal resistance of passive components are covered.

\section{REFERENCES}

[1] Z. Raud, V. Vodovozov, "Virtual Lab to Study Power Electronics in LabVIEW Framework", Electric Power Quality and Supply Reliability Conference, 2019.

[2] H. Amreiz, A. Al Janbey, M. Darwish, “A Practical Course for Teaching Electric Machines with Renewable Energy Sources", University Power Engineering Conference (UPEC), September 2018.

[3] M. Darwish, A. Al Janbey, H. Amreiz, "The Teaching of Switched Mode Power Supplies - Design, Simulation and Practical Implementation for Undergraduate and Postgraduate Students", IEEE University Power Engineering Conference (UPEC), September 2018.

[4] M. Darwish, B. R. Alamri, C. C. Marouchos, "OrCAD vs Matlab Simulink in Teaching Power Electronics", IEEE Proceedings of the 50th Universities Power Engineering Conference, September 2015.

[5] M. Darwish, C. C. Marouchos, "Modular OrCAD Simulation Approach in Teaching Power Electronics", IEEE Proceedings of the 49th Universities Power Engineering Conference, September 2014. 